\title{
AVALIAÇÃO DOS NÍVEIS DE PROTEÍNA C REATIVA CIRCULANTE E DO SNP rS1205 DO GENE CRP COM OBESIDADE, CARACTERÍSTICAS ANTROPOMÉTRICAS E MARCADORES BIOQUÍMICOS DE ESCOLARES
}

\author{
Elisa Inês Klinger ${ }^{1}$ \\ Pâmela Ferreira Todendi ${ }^{2}$ \\ Cézane Priscila Reuter ${ }^{3}$ \\ Michele Berger Ferreira ${ }^{4}$ \\ Miria Suzana Burgos ${ }^{5}$ \\ Andréia Rosane de Moura Valim ${ }^{6}$
}

\begin{abstract}
RESUMO
A obesidade é um grave problema de saúde pública e está relacionada a um baixo grau de inflamação crônica. A Proteína C Reativa (PCR) é caracterizada como proteína de fase aguda, mas em resposta à inflamação e em estados crônicos, pode assumir um papel próinflamatório, como no caso da obesidade. Para tanto, teve-se por objetivo avaliar a possível relação dos níveis de PCR circulante e do SNP rs1205 do gene CRP com obesidade, características antropométricas e marcadores bioquímicos em escolares de Santa Cruz do Sul - RS. Este estudo caracteriza-se por ser transversal retrospectivo, sendo realizado com 380 escolares de 07 a 17 anos de idade. A genotipagem do polimorfismo de nucleotídeo único (SNP) rs1205C/T foi realizada através de PCR em tempo real. Foram coletados dados antropométricos e realizados testes bioquímicos. O tratamento estatístico foi realizado por estatística descritiva, Kruskal-Wallis, Mann-Whitney e regressão logística multivariada. Com este estudo, foi observada prevalência de $25,3 \%$ de sobrepeso e obesidade nos escolares estudados, e que portadores do alelo de risco (T) apresentaram maior chance de desenvolver hipercolesterolemia (OR =2,67; 95\% IC: 1,265 - 5,657). O SNP rs1205 do gene CRP foi associado à hipercolesterolemia, podendo assim, aumentar o risco de problemas cardiovasculares na fase adulta.
\end{abstract}

Palavras-chave: Obesidade. Inflamação. PCR. Polimorfismo de nucleotídeo único. Escolares.

\footnotetext{
ABSTRACT

Obesity is a serious public health problem and it is related to a low grade of chronic inflammation. C-reactive protein (CRP) is characterized as acute phase protein and in response to inflammation CRP in chronic conditions, it may play a proinflammatory role, such as obesity. So far, the objective of this study is to evaluate the possible relationship between circulating CRP levels and the SNP rs1205 of the CRP gene with obesity,

${ }^{1}$ Aluna do Curso de Farmácia da Universidade de Santa Cruz do Sul - UNISC. <elisaklinger@hotmail.com>

2 Doutoranda em Patologia da Universidade Federal de Ciências da Saúde de Porto Alegre - UFCSPA <pamelaft@ibest.com.br>

3 Doutoranda em Ciências do Movimento Humano da Universidade Federal do Rio Grande do Sul - UFRGS <cpreuter@hotmail.com>

${ }^{4}$ Aluna do Curso de Farmácia da Universidade de Santa Cruz do Sul - UNISC. <mi_bergerf@ hotmail.com>

${ }^{5}$ Professora do Departamento de Educação Física e Saúde na Universidade de Santa Cruz do Sul - UNISC. <mburgos@unisc.br>

${ }^{6}$ Professora do Departamento de Biologia e Farmácia na Universidade de Santa Cruz do Sul - UNISC. <avalim@unisc.br>
} 
anthropometric characteristics and biochemical markers in school children in Santa Cruz do Sul - RS. A retrospective cross-sectional study was made with 380 schoolchildren aged from 07 to 17 years old. Genotyping of the single nucleotide polymorphism (SNP) rs1205C/T was performed by real time PCR. Anthropometric data were collected and performed biochemical tests. Statistical analysis was performed using descriptive statistics, Kruskal-Wallis, MannWhitney and multivariate logistic regression. This study observed prevalence of $25,3 \%$ of overweight and obesity among the evaluated schoolchildren and that carriers of the risk allele (T) are more propense to develop hypercholesterolemia ( $\mathrm{OR}=2,67 ; 95 \%$ IC: 1,265 - 5,657). The SNP rs1205 of the CRP gene was associated with risk of developing hypercholesterolemia, increasing the risk of cardiovascular problems in adulthood.

Keywords: Obesity. Inflammation. CRP. Single nucleotide polymorphism. Schoolchildren.

\section{INTRODUÇÃO}

Devido ao rápido aumento da prevalência de obesidade e as graves consequências para a saúde, a doença é considerada um dos desafios mais graves de saúde pública do início do século XXI (WHO, 2012). Portanto, deve haver um cuidado especial sobre o estado geral de saúde das crianças e dos adolescentes, pois diversos estudos demonstraram preocupantes índices de obesidade em crianças e jovens, bem como associação entre alguns fatores de risco para doenças cardiovasculares, apresentando assim, maior probabilidade de desenvolver doenças na fase adulta (BURGOS et al., 2010; PEDRONI et al., 2013; CASTILHO et al., 2014).

O sobrepeso e a obesidade vêm apresentando ascendente prevalência nos últimos anos, sendo estimado em 170 milhões de jovens menores de 18 anos com esta condição no mundo (WHO, 2012). O Brasil apresenta 17,5\% da sua população adulta obesa e 33,3\% apresentam sobrepeso, sendo que no Rio Grande do Sul, na capital Porto Alegre, a população apresenta 18\% de obesidade e 36\% de sobrepeso (BRASIL, 2013). Em Santa Cruz do Sul, estudos prévios apontam alta prevalência (25-27\%) de sobrepeso e obesidade em crianças e adolescentes em idade escolar (BURGOS et al., 2010; REUTER et al., 2013).

A Proteína C Reativa (PCR) é um marcador inflamatório importante e os níveis circulantes desta proteína podem ter um valor prognóstico na identificação de indivíduos com maior risco de desenvolver obesidade, diabetes mellitus tipo 2 e resistência à insulina, sendo que o gene da Proteína $\mathrm{C}$ Reativa $(C R P)$ está associado com glicose em jejum alterada e resistência à insulina (DURAN-GONZALEZ et al., 2011). Conforme Eiriksdottir et al. (2009), o gene CRP está relacionado com níveis circulantes de PCR de uma maneira 
dependente do Índice de Massa Corporal (IMC) e Circunferência da Cintura (CC), o que sugere uma influência de distribuição de gordura na produção de marcadores inflamatórios de baixo grau. Para tanto, teve-se por objetivo avaliar a possível relação dos níveis de PCR circulante e do SNP rs1205 do gene CRP com obesidade, características antropométricas e marcadores bioquímicos em escolares de Santa Cruz do Sul - RS.

\section{FUNDAMENTAÇÃO TEÓRICA}

A obesidade vem gerando consequências graves para a saúde da humanidade, sendo o IMC elevado um fator de risco para algumas das doenças referidas como não transmissíveis, tais como: doenças cardiovasculares (DCVs), diabetes mellitus tipo 2 e alguns tipos de câncer. As crianças vêm sofrendo com a obesidade cada vez mais cedo, além de serem mais propensas a terem complicações de saúde na fase adulta, sofrerem com reduções significativas na qualidade de vida e com um maior risco de provocações, intimidações e isolamento social (WHO, 2012).

A obesidade é cada vez mais reconhecida como uma doença de desordem inflamatória, sendo um fator determinante o consumo excessivo de calorias, o que provoca alterações morfológicas e metabólicas no tecido adiposo, bem como em outros sistemas e órgãos, como: pâncreas, hipotálamo, músculo esquelético e fígado. Estes processos levam a um infiltrado inflamatório no tecido adiposo de secreção endócrina e de citocinas, as quais promovem um aumento sistêmico da inflamação (BROOKS et al., 2010).

A PCR é assim denominada pela capacidade de precipitar o polissacarídeo-C da parede celular do Streptococcus pneumoniae, sua síntese é hepática e geralmente estimulada pela Interleucina-6, sendo a primeira proteína de fase aguda a ser descrita. É um sensível marcador inflamatório e de danos teciduais. O gene $C R P$, que codifica a proteína PCR, está localizado no cromossomo 1 (1q21-q23) com 224 resíduos e apresenta peso molecular de 25.106 kDa (PEPYS e HIRSCHFIELD, 2003).

Indivíduos obesos têm um risco aumentado para várias doenças crônicas, muitas das quais são também caracterizadas por concentrações elevadas de PCR. Como o tecido adiposo é uma fonte importante de citocinas pró-inflamatórias, tais como Interleucina-6 e TNF-alfa, elas aumentam a lipogênese hepática e desencadeiam uma resposta de fase aguda (RODRÍGUEZ-HERNÁNDEZ et al., 2013). Sendo assim, a PCR é um marcador inflamatório importante e os níveis circulantes desta proteína podem ter um valor prognóstico na 
identificação de indivíduos com maior risco de desenvolver obesidade, pois as evidências disponíveis sugerem que as variações na modulação metabólica de genes da PCR podem desempenhar um papel relevante na etiologia de desordens metabólicas relacionadas com a obesidade (DURAN-GONZALEZ et al., 2011).

\section{MATERIAIS E MÉTODOS}

Foi realizado um estudo transversal retrospectivo no município de Santa Cruz do Sul - RS no ano de 2012, com 380 escolares na faixa etária entre 07 e 17 anos de idade, provenientes de cinco escolas do município, selecionadas através de uma amostra de conveniência. As medidas antropométricas foram realizadas através do IMC, a partir das curvas de percentis do Centers for Disease Control and Prevention/National Center for Health Statistics (CDC/NCHS, 2000), de acordo com gênero e idade, considerando baixo peso $(<p 5)$, normal $(\geq p 5$ e $<p 85)$, sobrepeso $(\geq p 85$ e $<p 95)$ e obesidade $(\geq p 95)$. A CC foi avaliada através de fita métrica inelástica, utilizando como referência a parte mais estreita do tronco entre as costelas e a crista ilíaca e o quadril no nível do trocanter maior, sendo posteriormente classificada através dos critérios estabelecidos por Taylor et al. (2000), de acordo com sexo e idade, considerando circunferência normal percentil $\leq 80$ e obeso com percentil > 80. O Percentual de Gordura $(\% \mathrm{G})$ foi calculado através da equação de Slaugther et al. (1988), sendo posteriormente classificado de acordo com os dados de Lonman (1987) e separados em duas categorias: muito baixo/baixo/ótimo e moderadamente alto/alto/muito alto.

Os participantes foram instruídos a jejuar durante 12 horas para posterior coleta sanguínea. Os exames bioquímicos foram realizados com kits comerciais Kovalent (Kovalent do Brasil Ltda), tendo sido medidos os níveis de glicose, colesterol total (CT), lipoproteína de alta densidade (colesterol HDL) e triglicerídeos (TG), já a PCR foi mensurada com kits da DiaSys (DiaSysDiagnostic Systems, Alemanha), no equipamento MiuraOne (I.S.E., Roma, Itália). Para o CT, lipoproteína de baixa densidade (colesterol LDL), e TG os valores foram classificados em: aceitáveis, limítrofes e aumentados; para o colesterol HDL como: aceitáveis, limítrofes e baixos (NHLBI, 2012). O colesterol LDL foi calculado de acordo com a equação de Friedwald (1972). A glicose foi considerada como normal $<100 \mathrm{mg} / \mathrm{dL}$ e pré-diabetes 100 a $125 \mathrm{mg} / \mathrm{dL}$ (ADA, 2011). Os níveis de PCR foram medidos com ensaio de alta sensibilidade e classificados como: baixo, médio e alto, correspondendo a valores $\langle 1,0 ; 1,0-3,0$ e $>3,0$ $\mathrm{mg} / \mathrm{L}$, respectivamente (SHINE et al., 1981; PEARSON et al., 2003) e posteriormente 
reclassificados como normal e elevado. Escolares com valores de PCR acima de $10 \mathrm{mg} / \mathrm{L}$ foram excluídos do estudo por sugerir um processo inflamatório agudo (PEARSON et al., 2003).

Para a extração do material genético, utilizou-se sangue total anticoagulado com EDTA extraído através do método Salting out, conforme descrito por Miller, Dykes e Polesky (1988). A quantificação do DNA foi realizada com espectrofotômetro Nanodrop (Thermo Scientific, Waltham, MA). Levando em consideração que a população estudada é predominantemente de origem caucasiana (CARVALHO FILHO e MONASTERIO, 2012), o gene $C R P$ rs1205 foi selecionado pela relevância científica em população semelhante a ser estudada e por estar relacionado com inflamação de baixo grau em indivíduos com sobrepeso/obesidade. A avaliação da frequência alélica do polimorfismo foi identificada utilizando as informações do HapMap (2013). A genotipagem do SNP rs1205 foi realizada através de PCR em tempo real, utilizando o sistema Taqman ${ }^{\mathrm{TM}}$ no aparelho StepOne Plus ${ }^{\circledR}$ (AppliedBiosystems, Foster City, CA, EUA), conforme instruções do fabricante, utilizando ensaios de discriminação alélica. A genotipagem foi realizada em duplicata, apresentando precisão de $100 \%$.

O tratamento estatístico foi realizado no programa SPSS 20.0, por estatística descritiva a partir de média e desvio padrão para descrever as características dos sujeitos (Tabela 1). A distribuição da média de idade e níveis de PCR relacionado com características antropométricas e sexo foram realizadas através do teste de Kruskal-Wallis e Mann-Whitney (Tabela 2). A análise de regressão logística multivariada foi realizada para estimar as razões de chances entre o polimorfismo estudado com a zona (rural ou urbana), características antropométricas e marcadores bioquímicos (Tabela 3). O equilíbrio de Hardy-Weinberg (HWE) foi realizado e o $\mathrm{p}$ foi calculado usando $\chi^{2}$. Todos os participantes do estudo informaram a livre participação na pesquisa através da assinatura, pelos seus pais ou responsáveis, do Termo de Consentimento Livre e Esclarecido e os escolares concordaram em participar mediante Termo de Assentimento. O presente estudo foi avaliado pelo Comitê de Ética em Pesquisa da Universidade de Santa Cruz do Sul, sob protocolo de número $120.090 / 2012$. 


\section{RESULTADOS E DISCUSSÃO}

As características descritivas dos sujeitos estudados estão apresentadas na Tabela 1. A amostra foi composta por 380 escolares, sendo estes $55,5 \%$ do sexo feminino e $63,1 \%$ de adolescentes. A maioria residia na zona urbana, apresentando uma média de idade de 13,36 anos $( \pm 3,08)$. Foi possível observar que a amostra estudada de escolares de Santa Cruz do Sul - RS apresentou prevalência de 25,3\% de excesso de peso, sendo 15,8\% caracterizados com sobrepeso e 9,5\% com obesidade, conforme o IMC. Também foi identificado que 13,4\% dos escolares apresentaram CC elevada e 38,4\% alto \%G, resultados semelhantes ao encontrado em estudos prévios no mesmo município (BURGOS et al., 2010; REUTER et al., 2013). Assim também, quando comparado com um estudo brasileiro, verificamos semelhante prevalência de excesso de peso em escolares das diferentes regiões brasileiras $(27,6$ - 33,8\%) (FLORES et al., 2013).

Mendoza-Carrera et al. (2010) encontraram uma frequência relativamente alta de indivíduos com sobrepeso e obesidade em amostra de adolescentes mexicanos (27,2\%). Já um estudo realizado com jovens africanos, a prevalência de obesidade encontrada foi de 1,4 $5,5 \%$, resultado muito inferior quando comparado com mulheres e homens afrodescendentes dos EUA (63,8\% e 40,4\%, respectivamente) (LUKE et al., 2014). Estes resultados são mencionados por Keats e Wiggins (2014), como consequência do consumo excessivo de alimentos e o sedentarismo, os quais estão colaborando para esse grande percentual de sobrepeso e obesidade relatados na maioria dos estudos, principalmente nos países desenvolvidos e em desenvolvimento.

Dentre as características clínicas dos escolares, foram observados alto percentual de CT $(22,9 \%)$, LDL $(37,1 \%)$ e glicose $(23,9 \%)$, sendo ainda que $6,1 \%$ apresentaram HDL baixo e $8,2 \%$ TG aumentado. I'Allemand et al. (2008) realizaram um estudo com crianças com excesso de peso e constataram que a obesidade teve uma forte associação com a dislipidemia aterogênica. As concentrações de um ou mais dos lipídios foram anormais em 32\%, sendo colesterol total em 14,1\% dos casos analisados, LDL em 15,8\%, HDL em 11,1\% e TG em 14,3\%. Alterações lipídicas são preocupantes, uma vez que as placas ateromatosas podem iniciar seu desenvolvimento na infância e adolescência, apresentando relação direta com o perfil lipídico (SERRANO et al., 2010).

Neste estudo, foi observado que 10,3\% dos escolares apresentaram níveis elevados de PCR, que é um marcador inflamatório importante, e os níveis circulantes desta proteína 
podem ter um valor prognóstico na identificação de indivíduos com maior risco de desenvolver obesidade, diabetes mellitus tipo 2 e resistência à insulina (DURANGONZALEZ et al., 2011).

A distribuição das frequências genotípicas e alélicas observadas para o SNP rs1205 estavam em equilíbrio de Hardy-Weinberg $(p>0,05)$. Foi observada frequência alélica de $60,4 \%$ para o alelo C, e, 39,6\% para o alelo T, frequência semelhante encontrada por Halder et al. (2010), os quais observaram uma frequência de $67 \%$ para o alelo C e $33 \%$ para o alelo T e por Kolz et al. (2008), com frequência de 66,8\% para o alelo C e 33,2\% para o alelo $\mathrm{T}$ em adultos europeus. Duran-Gonzalez et al. (2011) estudaram jovens mexicanos e encontraram pequena variação na frequência genotípica quando comparado com o presente estudo (CC 40,4\%, TC 49,5\% e TT 10,1\%); já Lin et al. (2014) encontraram frequências genotípicas e alélicas diferentes, sendo que observaram para CC 19,6\%, TC 48,6\%, TT 31,8\%, T 56,1\% e C 43,9\%; no entanto, trata-se de uma população oriental. 
Tabela 1. Características descritivas dos escolares.

\begin{tabular}{|c|c|c|}
\hline & $\mathrm{n}=\mathbf{3 8 0}(\%)$ & Média ( \pm DP) \\
\hline \multicolumn{3}{|l|}{ Sexo } \\
\hline Feminino & $211(55,5)$ & \\
\hline Masculino & $169(44,5)$ & \\
\hline Faixa Etária* & & $13,36( \pm 3,08)$ \\
\hline Criança & $140(36,9)$ & \\
\hline Adolescente & $240(63,1)$ & \\
\hline \multicolumn{3}{|l|}{ Localização } \\
\hline Rural & $140(36,8)$ & \\
\hline Urbana & $240(63,2)$ & \\
\hline $\operatorname{IMC}\left(\mathrm{kg} / \mathrm{m}^{2}\right)$ & & $20,66( \pm 3,93)$ \\
\hline Baixo Peso/Normal & $284(74,7)$ & \\
\hline Sobrepeso & $60(15,8)$ & \\
\hline Obesidade & $36(9,5)$ & \\
\hline $\mathrm{CC}(\mathrm{cm})$ & & $66,80( \pm 9,13)$ \\
\hline Normal & $329(86,6)$ & \\
\hline Elevada & $51(13,4)$ & \\
\hline$\% \mathrm{G}$ & & $21,05( \pm 7,53)$ \\
\hline Muito baixo, baixo e ótimo & $234(61,6)$ & \\
\hline Moderadamente alto, alto e muito alto & $146(38,4)$ & \\
\hline Colesterol Total (mg/dL) & & $177,79( \pm 34,52)$ \\
\hline Normal & $293(77,1)$ & \\
\hline Aumentado & $87(22,9)$ & \\
\hline Colesterol LDL (mg/dL) & & $123,10( \pm 32,33)$ \\
\hline Normal & $239(62,9)$ & \\
\hline Aumentado & $141(37,1)$ & \\
\hline Colesterol HDL (mg/dL) & & $54,68( \pm 10,36)$ \\
\hline Normal & $357(93,9)$ & \\
\hline Baixo & $23(6,1)$ & \\
\hline Triglicerídeos (mg/dL) & & $75,64( \pm 33,05)$ \\
\hline Normal & $349(91,8)$ & \\
\hline Aumentado & $31(8,2)$ & \\
\hline Glicose (mg/dL) & & $92,42( \pm 11,81)$ \\
\hline $\begin{array}{l}\text { Normal } \\
\text { Elevado }\end{array}$ & $\begin{array}{c}289(76,1) \\
91(23,9)\end{array}$ & \\
\hline Proteína C Reativa (mg/L) & & $1,05( \pm 1,52)$ \\
\hline Normal & $341(89,7)$ & \\
\hline Elevado & $39(10,3)$ & \\
\hline$C R P$ SNP rs 1205 & & $p=0,891 * *$ \\
\hline $\mathrm{T}$ & $301(39,60)$ & \\
\hline $\mathrm{C}$ & $459(60,40)$ & \\
\hline $\mathrm{TT}$ & $62(16,3)$ & \\
\hline $\mathrm{TC}$ & $177(46,6)$ & \\
\hline $\mathrm{CC}$ & $141(37,1)$ & \\
\hline
\end{tabular}

*Faixa Etária: criança <12 anos, adolescente 12-17 anos. ** WHE.

Foi possível observar, no presente estudo, que indivíduos com sobrepeso, obesidade e CC elevada são mais jovens em relação aos escolares com esses indicadores em taxas 
normais; no entanto, os indivíduos com \%G elevado apresentam idade superior aos com esses indicadores em taxas normais (Tabela 2). Também foi observado que os níveis de PCR circulantes se elevaram conforme aumentaram as medidas antropométricas, pois indivíduos com sobrepeso e obesidade apresentam maiores níveis quando comparados com os normais. Da mesma forma, os escolares com maiores medidas de $\mathrm{CC}$, elevado $\% \mathrm{G}$ e indivíduos do sexo feminino apresentam maiores níveis de PCR circulante.

Tabela 2. Distribuição da média de idade e níveis de PCR relacionado com características antropométricas e sexo.

\begin{tabular}{|c|c|c|c|}
\hline \multicolumn{2}{|r|}{ Características } & Idade (anos) & $\begin{array}{c}\text { PCR } \\
(\mathrm{mg} / \mathrm{L})\end{array}$ \\
\hline \multirow[t]{4}{*}{ IMC* } & Baixo peso/normal & $13,59 \pm 3,03$ & $0,90 \pm 1,37$ \\
\hline & Sobrepeso & $13,08 \pm 2,98$ & $1,25 \pm 1,80$ \\
\hline & Obesidade & $11,97 \pm 3,30$ & $1,92 \pm 1,82$ \\
\hline & Valor de $p$ & 0,011 & 0,000 \\
\hline \multirow[t]{3}{*}{$\mathrm{CC}^{* *}$} & Normal & $13,47 \pm 3,05$ & $0,96 \pm 1,43$ \\
\hline & Elevada & $12,63 \pm 3,19$ & $1,62 \pm 1,93$ \\
\hline & Valor de $p$ & 0,068 & 0,001 \\
\hline \multirow[t]{3}{*}{$\% G^{* *}$} & Muito baixo, baixo e ótimo & $13,02 \pm 3,17$ & $0,91 \pm 1,52$ \\
\hline & Moderadamente alto, alto e muito alto & $13,90 \pm 2,86$ & $1,27 \pm 1,50$ \\
\hline & Valor de $p$ & 0,011 & 0,000 \\
\hline \multirow[t]{3}{*}{ Sexo $^{* *}$} & Feminino & $13,38 \pm 3,09$ & $1,18 \pm 1,61$ \\
\hline & Masculino & $13,33 \pm 3,09$ & $0,89 \pm 1,40$ \\
\hline & Valor de $p$ & 0,914 & 0,043 \\
\hline
\end{tabular}

Valores expressos em média e desvio padrão, *Kruskal-Wallis, **Mann-Whitney; nível de significância $p<0,05$.

Alguns estudos relatam que existe um aumento significativo nos níveis séricos de PCR com o aumento do IMC (EIRIKSDOTTIR et al., 2009; RIUS-OTTENHEIM et al., 2012). Alfaro et al. (2012) observaram que o aumento do IMC e os níveis elevados de PCR no soro são mais elevados em mulheres do que em homens, e que estes resultados indicam um efeito indireto no aumento do tecido adiposo e sobre a secreção de citocinas pró-inflamatórias que regulam a síntese e secreção de PCR.

De acordo com os resultados encontrados, Noronha et al. (2013) observaram níveis mais elevados de PCR em indivíduos que eram obesos e nas faixas etárias menores. Os valores de PCR aumentaram com o incremento do IMC, tendo uma prevalência de PCR elevada três vezes maior em obesos. Halder et al. (2010) também encontraram níveis mais elevados de PCR associados com IMC elevado. Da mesma forma, dois estudos observaram 
que os níveis de PCR estão relacionados com o aumento do IMC, sendo que Bochud et al. (2009) relataram um incremento maior em mulheres, e explica que isso se deve principalmente à massa gorda, enquanto outro argumenta que não há nenhuma evidência que os níveis de PCR estão relacionados com o aumento da adiposidade, pois apresentam a hipótese de que níveis elevados de PCR são gerados por uma maior adiposidade, sem evidências de que a elevação dos níveis de PCR por si só contribuem para a deposição de gordura (WELSH et al., 2010).

Na Tabela 3, é possível visualizar que indivíduos portadores do alelo T apresentaram maior chance de desenvolver hipercolesterolemia ( $\mathrm{OR}=2,675$; 95\% IC: 1,265 - 5,657). Assim também, escolares portadores do alelo $\mathrm{T}$ apresentaram maiores chances de alterações no IMC, nos níveis de PCR, HDL, TG e glicose, porém o intervalo de confiança apresentou grande amplitude. O alelo T não apresentou influência sobre a CC, \%G e LDL alterados.

Tabela 3. Relação do SNP rs1205 com medidas antropométricas e marcadores bioquímicos.

\begin{tabular}{|c|c|}
\hline Variáveis & $\begin{array}{c}\text { PCR rs1205 } \\
\text { CT+TT } \\
\text { OR }(95 \% \text { IC })\end{array}$ \\
\hline Zona & $0,866(0,556-1,349)$ \\
\hline IMC & $1,572(0,831-2,971)$ \\
\hline $\mathrm{CC}$ & $0,574(0,269-1,227)$ \\
\hline$\% \mathrm{G}$ & $0,790(0,478-1,304)$ \\
\hline PCR & $1,207(0,579-2,518)$ \\
\hline HDL & $1,644(0,611-4,426)$ \\
\hline LDL & $0,769(0,415-1,426)$ \\
\hline $\mathrm{CT}$ & $2,675^{*}(1,265-5,657)$ \\
\hline TG & $1,282(0,506-3,246)$ \\
\hline Glicose & $1,140(0,684-1,900)$ \\
\hline
\end{tabular}

Um estudo realizado com europeus sobreviventes de infarto do miocárdio revelou que o aumento do IMC e do colesterol total foi associado com maiores concentrações de PCR circulantes; no entanto, a presença do alelo T não teve influência sobre este aumento (KOLZ et al., 2008). Porém, estudo francês relatou que a presença do alelo T está relacionada com maiores níveis de PCR circulantes (ANCELIN et al., 2015). De acordo com a pesquisa de $\mathrm{Hu}$ et al. (2010), observou-se relação do polimorfismo rs1205 com CC, diabetes mellitus, TG e HDL em adultos chineses, mas não houve relação deste polimorfismo com CT, nem com 
parâmetros estabelecidos para obesidade. Em jovens mexicanos, Duran-Gonzalez et al. (2011) observaram uma associação do alelo T com glicose em jejum e resistência à insulina.

O presente estudo apresenta algumas limitações, como a ausência de avaliação das características étnicas, tamanho amostral e a análise restrita a um SNP. Diversos outros genes estão envolvidos na síntese de PCR, desta forma novos estudos são necessários ampliando o número de participantes e polimorfismos relacionados com níveis de PCR e obesidade, assim como a ampliação do número de genes.

\section{CONCLUSÃO}

Com os dados deste estudo, é possível observar elevada prevalência de obesidade e sobrepeso nos escolares, além de verificar que os níveis de PCR circulantes elevaram-se conforme aumentaram as medidas antropométricas, bem como a associação do SNPs rs1205 do gene CRP com o risco de desenvolver hipercolesterolemia. Estes resultados podem contribuir para a compreensão dos processos metabólicos relacionados à obesidade/sobrepeso, prevenindo complicações na fase adulta e alertar sobre o risco que o excesso de peso representa para a saúde das crianças.

\section{AGRADECIMENTOS}

Agradecemos à Universidade de Santa Cruz do Sul - UNISC, à Fundação de Amparo à Pesquisa do Estado do Rio Grande do Sul (FAPERGS) pelo financiamento através do Edital Pesquisador Gaúcho n ${ }^{\circ}$ 001/2013 de processo no 1886-2551/13-0 e ao Programa de Pós-Graduação em Promoção da Saúde (PPGPS/UNISC). Os autores também agradecem aos escolares, pais e professores e aos voluntários por participarem da pesquisa.

\section{REFERÊNCIAS}

ALFARO, E. F. et al. Common variants in the $C R P$ gene are associated with serum C-reactive protein levels and body mass index in healthy individuals in Mexico. Genetics and Molecular Research, n. 3, v. 11, p. 2258-2267, maio 2012. 
AMERICAN DIABETES ASSOCIATION (ADA). Diagnosis and classification of diabetes mellitus. Diabetes Care, v. 34, n. 1, p. S62-9, jan. 2011.

ANCELIN, M. L. et al. C-reactive protein gene variants: independent association with latelife depression and circulating protein levels. Translational Psychiatry, v. 5, p. 01-08, jan. 2015.

BOCHUD, M. et al. Association between C-reactive protein and adiposity in women. The Journal of Clinical Endocrinology \& Metabolism, v. 94, p. 3969-3977, 2009.

BROOKS, G. C. et al. Relation of C-reactive protein to abdominal adiposity. American Journal of Cardiology, n. 1, v. 106, p. 56-61, maio 2013.

BURGOS, M. S. et al. Comparison analysis of blood pressure, obesity, and cardio-respiratory fitness in schoolchildren. Arquivos Brasileiros de Cardiologia, n. 6, v. 94, p. 739-744, maio 2010.

CARVALHO FILHO, I. de; MONASTERIO, L. Immigration and the origins of regional inequality: Government-sponsored European migration to southern Brazil before World War I. Regional Science and Urban Economics, n. 5, v. 42, p. 794-807, set. 2012.

CASTILHO, S. D. et al. Prevalence of weight excess according to age group in students from Campinas, SP, Brazil. Revista Paulista de Pediatria, n. 2, v. 32, p. 200-206, jun. 2014.

Centers for Disease Control and Prevention/National Center for Health Statistics (CDC/NCHS, 2000). Disponível em: http://www.cdc.gov/growthcharts. Acesso em: dez. 2013.

DURAN-GONZALEZ, J. et al. Association study of candidate gene polymorphisms and obesity in a young Mexican-American population from South Texas. Archives of Medical Research, n. 6, v. 42, p. 523-531, ago. 2011.

EIRIKSDOTTIR, G. et al. The interaction of adiposity with the CRP gene affects CRP levels: age gene/environment susceptibility - Reykjavik study. International Journal of Obesity, Londres, n. 2, v. 33, p. 267-272, fev. 2009.

FLORES, L. S. et al. Trends of underweight, overweight, and obesity in Brazilian children and adolescents. Jornal de Pediatria, Rio de Janeiro, n. 5, v. 89, p. 456-61, set./out. 2013.

HALDER, I. et al. Polymorphisms in the $C R P$ gene moderate an association between depressive symptoms and circulating levels of C-reactive protein. Brain, Behaviour and Immunity, n. 1, v. 24, p. 160-167, jan. 2010.

HAPMAP. National Institutes of Health: International HapMap Project. Disponível em: http://www.ncbi.nlm.nih.gov. Acesso em: dez. de 2013.

HU, M. et al. Effect of central obesity, low high-density lipoprotein cholesterol and C-reactive protein polymorphisms on C-reactive protein levels during treatment with Rosuvastatin (10 mg Daily). The American Journal of Cardiology, n. 11, v. 106, p. 1588-1593, dez. 2010. 
I'ALLEMAND, D. et al. Cardiovascular risk in 26,008 European overweight children as established by a multicenter database. Obesity, n. 7, v. 16, p. 1672-1679, jul. 2008.

KEATS, S.; WIGGINS, S. Future diets: implications for agriculture and food prices. ODI Report. London: Overseas Development Institute, jan. 2014.

KOLZ, M. et al. DNA variants, plasma levels and variability of C-reactive protein in myocardial infarction survivors: results from the AIRGENE study. European Heart Journal, n. 10 , v. 29, p. 1250-1258, maio 2008.

LIN, C. et al. Association of CRP gene polymorphisms with serum CRP level and handgrip strength in community-dwelling elders in Taiwan: Taichung Community Health Study for Elders (TCHS-E). Experimental Gerontology, v. 57, p. 141-148, set. 2014.

LOHMAN, T. G. The use of skinfold to estimate body fatness on children and youth. Journal of Physical Education, Recreation \& Dance, n. 9, v. 58, p. 98-102, nov./dez. 1987.

LUKE, A. et al. A mixed ecologic-cohort comparison of physical activity \& weight among young adults from five populations of African origin. BMC Public Health, v. 14, p. 397, 2014.

MENDOZA-CARRERA, F. et al. Influence of CRP, IL6, and TNFA gene polymorphisms on circulating levels of $\mathrm{C}$-reactive protein in Mexican adolescents. Archives of Medical Research, v. 41, p. 472-477, 2010.

MILLER, S. A.; DYKES, D. D.; POLESKY, H. F. A simple salting out procedure for extracting DNA from human nucleated cells. Nucleic Acids Research, n. 3, v. 16, p. 1215, fev. 1988.

MINISTÉRIO DA SAÚDE. Vigilância de fatores de risco e proteção para doenças crônicas por inquérito telefônico. 2013.

NATIONAL HEART, LUNG, AND BLOOD INSTITUTE (NHLBI). Expert panel on integrated guidelines for cardiovascular health and risk reduction in children and adolescents. NIH Publication, n. 12-7486A, 2012.

NORONHA, J. A. F. et al. C-reactive protein and its relation to high blood pressure in overweight or obese children and adolescents. Revista Paulista de Pediatria, São Paulo, n. 3, v. 31, p. 331-337, set. 2013.

PEARSON, T. A. et al. Markers of inflammation and cardiovascular disease - application to clinical and public health practice: a statement for healthcare professionals from the Centers for Disease Control and Prevention and the American Heart Association. Circulation, v. 107, p. 499-511, 2003.

PEDRONI, J. L. et al. Prevalência de obesidade abdominal e excesso de gordura em escolares de uma cidade serrana no sul do Brasil. Ciência \& Saúde Coletiva, Rio de Janeiro, n. 5, v. 18, p. 1417-1425, maio 2013.

PEPYS, M. B.; HIRSCHFIELD, G. M. C-reactive protein: a critical update. The Journal of Clinical Investigation, n. 12, v. 111, p. 1805-1812, jun. 2003. 
REUTER, C. P. et al. Prevalence of obesity and cardiovascular risk among children and adolescents in the municipality of Santa Cruz do Sul, Rio Grande do Sul. São Paulo Medical Journal., n. 5, v. 131, p. 323-330, 2013.

RIUS-OTTENHEIM, N. et al. C-reactive protein haplotypes and dispositional optimism in obese and nonobese elderly subjects. Inflammation Research, n. 1, v. 61, p. 43-51, jan. 2012.

RODRÍGUEZ-HERNÁNDEZ, $H$. et al. Obesity and inflammation: epidemiology, risk factors, and markers of inflammation. International Journal of Endocrinology, v. 2013, p. 11, abr. 2013.

SERRANO, H. M. S. et al. Body composition, biochemical and clinical changes of adolescents with excessive adiposity. Arquivos Brasileiros de Cardiologia, São Paulo, n. 4, v. 95 , p. 464-472, out. 2010.

SHINE, B. et al. Solid phase radioimmunoassays for human C-reactive protein. Clinica Chimica Acta, n. 1, v. 117, p. 13-23, nov. 1981.

SLAUGHTER, M. H. et al. Skinfold equations for estimation of body fatness in children and youth. Human Biology, n. 5, v. 60, p. 709-723, out. 1988.

TAYLOR, R. W. et al. Evaluation of waist circumference, waist-to-hip ratio, and the conicity index as screening tools for high trunk fat mass, as measured by dual-energy X-ray absorptiometry, in children aged 3-19 y. The American Journal of Clinical Nutrition, n. 2, v. 72, p. 490-495, ago 2000.

WELSH, P. et al. Unraveling the directional link between adiposity and inflammation: a bidirectional Mendelian randomization approach. The Journal of Clinical Endocrinology Metabolism, n. 1, v. 95, p. 93-99, jan. 2010.

WORLD HEALTH ORGANIZATION (WHO). Population-based approaches to childhood obesity prevention. Disponível em: <http://www.who.int/dietphysicalactivity/ childhood/approaches/en/>. Acesso em: jan. 2015. 